The Role of Emerging Economies in the Global Price Formation Process of Commodities: Evidence from Brazilian and U.S. Coffee Markets

Martin T. Bohl ${ }^{\dagger}$, Christian Gross ${ }^{\dagger}$ and Waldemar Souza ${ }^{\ddagger}$

$51 / 2016$

${ }^{\dagger}$ Department of Economics, University of Münster, Germany

${ }^{\ddagger}$ Federal University of Alagoas, Brazil 


\title{
The Role of Emerging Economies in the Global Price Formation Process of Commodities: Evidence from Brazilian and U.S. Coffee Markets*
}

\author{
Martin T. Bohl ${ }^{\dagger}$, Christian Gross ${ }^{\ddagger}$ and Waldemar Souza ${ }^{\S}$
}

July 27,2016

\begin{abstract}
This paper examines the role of the Brazilian futures exchange, BM\&F Bovespa, in the global price formation process of Arabica coffee. Using a multivariate GARCH model we find bi-directional information transmission in terms of spillover effects between the BM\&F Bovespa futures contract for Arabica coffee and the 'Coffee C' futures contract traded at the Intercontinental Exchange (ICE) in New York. Moreover, our empirical results indicate that the influence of the BM\&F Bovespa futures market on the ICE futures market increased during the 2010-2012 boom in coffee prices, suggesting a greater role of local information for volatility dynamics during this period. We also show that local Brazilian spot markets incorporate information from both the domestic and the foreign futures market. Taken together, our findings highlight the great relevance of the $\mathrm{BM} \& \mathrm{~F}$ Bovespa futures market in the global price formation process of Arabica coffee.
\end{abstract}

JEL Classification: G12, G13, G14, G15, Q02

Keywords: Commodity futures markets, cross-border volatility transmission, emerging futures exchanges, price spikes in commodity markets

${ }^{*}$ We thank Philipp Adämmer for helpful comments and Renata Alves (BM\&F Bovespa) for providing us with details on institutional characteristics of the BM\&F Bovespa futures exchange.

${ }^{\dagger}$ Corresponding author: Department of Economics, University of Münster, Am Stadtgraben 9, 48143 Münster, Germany, Phone: +49 25183 25005, Fax: +49 25183 22846, E-Mail: martin.bohl@wiwi.unimuenster.de.

${ }^{\ddagger}$ University of Münster, Germany

${ }^{\S}$ Federal University of Alagoas, Brazil 


\section{Introduction}

Futures and options trading in emerging economies has witnessed rapid growth in the past decade. Measured in terms of trading volume, there were seven derivatives exchanges located in emerging economies among the world's 20 largest exchanges in 2005. By 2015, this figure nearly doubled to twelve. One category of derivative contracts that has contributed disproportionately to this growing trend is commodity futures trading (FIA 2006, 2016). The success of futures trading in emerging economies has been fostered by the gradual implementation of financial sector reforms aimed at improving the regulatory framework of futures exchanges. One major component of these policy measures was the opening of futures trading to foreign investors. Non-residents are now allowed to trade at many of the largest derivatives exchanges in emerging markets, including BM\&F Bovespa, Moscow Exchange, Korea Exchange, Johannesburg Stock Exchange, and Taiwan Futures Exchange. ${ }^{1}$

The growing importance of commodity futures trading involves both benefits and risks. Since some emerging markets depend on only a few commodities for their export activities, their domestic producers are more exposed to volatility shocks in commodity prices than diversified producers in developed economies. Therefore, the risk transfer offered by futures trading is particularly beneficial to market participants in emerging economies (Lien and Zhang 2008). Another major benefit is the facilitation of information transmission due to institutional advantages of futures markets relative to underlying spot markets, including higher liquidity, more transparency, and lower transaction costs (Working 1962; Black 1976). In this context, the presence of foreign traders can contribute to a faster transmission of global information into local market prices, thereby improving informational efficiency (Bae et al. 2012).

Yet, there are also potential risks associated with increased commodity futures trading in emerging economies. One frequently raised concern is that speculative trading in futures

\footnotetext{
${ }^{1}$ There are, however, still strict regulations for non-resident investors at the derivatives exchanges in China and India, where trading by foreigners is effectively prohibited for most futures contracts. We obtained all information on regulations for foreign investors from the exchanges' websites.
} 
markets causes excess volatility in underlying spot markets (e.g., Antoniou and Holmes 1995; Lien and Zhang 2008). In addition, the liberalization of emerging futures markets may entail destabilizing effects through herding behavior and positive feedback trading by foreign investors, causing price dynamics that are unrelated to economic fundamentals (Ghysels and Seon 2005). A large body of literature is devoted to the role played by foreign investors during episodes of financial crises in emerging economies (e.g., Choe et al. 1999; Kaminsky et al. 2004; Chen et al 2008).

Liberalizing commodity futures markets should, in principle, lead to a large degree of interdependence with world markets. This may have important repercussions for commodityproducing emerging economies, since global price shocks can affect local markets more directly. Especially against the background of the recent price and volatility spikes in international commodity markets (FAO 2011), it is therefore crucial to assess how local markets in commodity-producing emerging economies interact with global commodity markets.

This paper addresses this topic by analyzing the role of Brazil in the global price formation process of Arabica coffee. We use a trivariate multivariate generalized autoregressive conditional heteroskedasticity (MGARCH) model with the BEKK representation proposed by Engle and Kroner (1995) to identify the nature and extent of cross-border information transmission. In particular, we focus on price and volatility linkages of Brazilian futures and spot markets with the global benchmark, the 'Coffee C' futures contract, which is traded at the Intercontinental Exchange (ICE) in New York. According to data from the Foreign Agricultural Service (FAS) of the United States Department of Agriculture (USDA), Brazil is the world's largest Arabica coffee producer. Its total production was 38 million 60-kilogram-bags in the marketing year (July-June) 2014/15, which is equivalent to a global market share of 44 percent. As a consequence of the hedging needs by domestic Brazilian producers and merchants, the Arabica futures contract of the BM\&F Bovespa in São Paulo was actively traded over the past decade, as evidenced by its average trading volume of about 351 thousand contracts per year during 2005-2015. In addition to domestic traders, a large proportion of 
this trading activity was accounted for by foreign investors, who, at times, held almost half of all positions in this market. Our paper contributes to the literature in several ways.

First, previous literature on the role of emerging economies in the global price formation process of commodities has almost exclusively focused on international linkages of Chinese markets (e.g., Hua and Chen 2007; Fung et al. 2010; Liu and An 2011; Han et al. 2013; Yin and Han 2013; Hernandez et al. 2014). ${ }^{2}$ By investigating the process of cross-border information transmission in Brazilian markets, which are characterized by a very different institutional setting compared to the highly regulated markets in China, we present further evidence on the functioning of commodity markets in emerging economies. Moreover, in contrast to earlier studies, we do not solely examine international dependencies between futures exchanges, but we also consider spot markets in our analysis. ${ }^{3}$ This is important since price and volatility dynamics in spot markets may be more relevant for many market participants than those in the futures market.

Second, our paper aims to improve the understanding of volatility transmissions during periods of large price spikes in commodity markets. Between 2010 and 2012, Arabica coffee markets experienced a pronounced boom period with price increases of more than 100 percent, followed by a collapse of prices shortly after. We are interested in ascertaining whether cross-border volatility linkages changed during this period of price spikes. To this end, we modify our baseline MGARCH model by including a dummy variable that allows the cross-border spillover parameters to shift in this specific period. This approach enables us to identify whether local or global market news were more relevant for volatility dynamics during this time span.

Our findings indicate that there is a bi-directional relationship in terms of price and

\footnotetext{
${ }^{2}$ In addition, there are a few studies that analyze international price and volatility dependencies of commodity markets located in mature economies. For example, Adämmer et al. (2016) focus on price and volatility transmission between European and U.S. commodity futures exchanges, Booth and Ciner (1997) conduct an analysis of the interaction between corn futures prices at the Chicago Board of Trade and the Tokyo Grain Exchange, and Tse and Booth (1997) examine information transmission between oil futures markets in New York and London.

${ }^{3}$ The only exception is the study by Liu and An (2011), which includes both Chinese futures and spot prices for copper and soybean.
} 
volatility spillovers between the Brazilian futures market for Arabica coffee and the ICE global benchmark. This shows that local and global information about supply and demand fundamentals is rapidly transmitted from one futures exchange to the other. Moreover, the bi-directional nature of information transmission emphasizes the prominent role of the BM\&F Bovespa futures exchange in the global price formation process of Arabica coffee. Our results for Brazilian spot markets suggest that they respond to price changes in the foreign futures market, but volatility linkages are rather weak. Our separate analysis of volatility spillovers during the large boom period in 2010-2012 reveals a shift in volatility spillovers from the Brazilian futures market to the U.S., but not vice versa. The minor influence of U.S. futures market shocks on local markets during the turbulent period is consistent with the fact that participation by foreign traders in the Brazilian futures market was very low during this episode. We therefore conclude that local market information was more relevant than global market information in explaining the price and volatility spikes.

The remainder of the paper is structured as follows. In Section 2 we provide an overview of the institutional background for Brazilian coffee markets. We then outline our empirical approach in Section 3. Section 4 presents the data and Section 5 discusses the empirical results. Section 6 summarizes our findings and concludes.

\section{Institutional Background}

The history of commodity futures trading in Brazil dates back until 1917 when the São Paulo Commodities Exchange (Bolsa Brasileira de Mercadorias) was established. In the following decades it offered a variety of forward contracts for several commodities that were central to Brazil's commodity-based economy, including cotton, coffee and live cattle. ${ }^{4}$ In 1991 , the São Paulo Commodities Exchange merged with the Brazilian Mercantile and Futures Exchange (BM\&F) and in 2008 with the São Paulo Stock Exchange Bovespa to form BM\&F Bovespa. It is now the only futures exchange in Brazil and the largest one in Latin America

\footnotetext{
${ }^{4}$ However, trading in commodity forwards was often suspended during this early period due to e.g., government interventions or a lack of market demand (see De Mello 2006).
} 
based on overall trading volume. The Arabica coffee contract in its current form exists since 1978 (UNCTAD 2009).

Until January 2000, the trading of agricultural commodity derivatives at the BM\&F Bovespa was restricted to residents in Brazil. This changed when the Central Bank of Brazil enacted Resolution 2687, which enabled access of non-resident investors to the Brazilian agricultural derivatives markets. ${ }^{5}$ Under this new regulation, non-resident investors can register with the BM\&F Bovespa via one of the authorized brokerage houses. The settlement of trades is then executed in U.S. dollar through a specific settlement account in New York City. In the case where a non-resident buyer takes delivery of the underlying commodity from a resident seller, it is the buyer's responsibility to arrange for the shipment of the purchased commodity to the foreign export market.

It is essential for our research question to have knowledge about the extent of foreign investor participation in the BM\&F Bovespa futures market. The international finance literature provides evidence that foreign investors have different resources and capabilities in processing market information relative to local investors (see e.g., Bae et al. 2012 and Webb et al. 2016). Figure 1(a) plots the weekly share of non-resident investors in combined open interest, i.e., the aggregate of long and short positions, in the Brazilian futures market for Arabica coffee in the period from January 2, 2003 until July 2, 2015. ${ }^{6}$ Figure 1(b) breaks down the data by long and short positions. Two important patterns can be derived from Figures 1(a) and (b). First, although foreign investors' participation fluctuated over the depicted period, this investor group generally accounted for a large share of open interest. The proportion of aggregate positions held by foreigners reached up to 45 percent. With regards to long positions, the maximum share was almost 70 percent. Second, starting at the end of 2009,

\footnotetext{
${ }^{5}$ We use the terms non-resident investors and foreign investors interchangeably, even though it may be possible that foreign investors operate through local Brazilian branches or intermediaries. Any details on the regulations for non-resident investors may be found on the BM\&F Bovespa website.

${ }^{6}$ Our source for the data on investor positions is the BM\&F Bovespa website. The BM\&F Bovespa differentiates between five categories of investors: institutional investors, individuals, banks, corporations and non-resident investors. Until December 2009, the data was released in daily frequency, thereafter the exchange switched to weekly frequency (every Thursday). For reasons of consistency, we transform the daily data to weekly frequency.
} 
foreign investors' activity declined markedly, reaching its low of roughly 1 percent in August 2011. Thereafter, foreign traders began to increase their activity again.

[FIGURE 1 about here]

As can be seen from Figure 2, this pronounced retreat of foreign investors coincided with the unprecedented boom in Arabica coffee prices between 2010 and 2012. During this time span, coffee prices initially more than doubled from roughly 160 to almost 400 U.S. dollar per $60 \mathrm{~kg}$ bag in less than one year. Prices then remained highly volatile throughout 2011 and finally collapsed at the beginning of 2012. How can we rationalize this sharp decline in foreign investors' activity shortly before and during the period of large price spikes?

[FIGURE 2 about here]

One way of providing an explanation is to analyze foreigners' motivations in their decisionmaking process. Foreign hedgers face the decision whether to hedge their price risk in the U.S. or the Brazilian futures market. One key criterion in their decision will be current and expected dynamics in the basis - the difference between the spot and the futures price - in each of these two futures markets. It is well documented that hedgers pay close attention to trends in the basis (Peck 1976; CBOT 2004). The reason for this is that unpredicted fluctuations in the basis have adverse effects on the hedging effectiveness in that profits (losses) from a futures market transaction are not sufficient to offset losses (profits) from the spot market transaction. In the presence of this basis risk, it is essential for hedgers to form expectations about future basis changes before making their hedging decisions (Kuserk 2010). Consequently, the predictability of the basis is crucial for attracting hedgers, as increased basis risk impairs the risk management capacity of futures trading (Leuthold 1994; Garcia and Sanders 1996).

In our setting, foreign coffee hedgers compare the extent of basis risk in the Brazilian vis-à-vis the U.S. futures market and will choose the market which exposes them to a lower 
basis risk. Accordingly, expectations about future changes in the spread between U.S. and Brazilian futures prices influence foreign hedgers' decisions where to place their hedge. ${ }^{7}$

Figure 3 depicts the spread between U.S. and Brazilian futures prices during 2003-2015. The spread is positive for the most part of the sample period, indicating that futures prices in the U.S. were almost always above futures prices in Brazil. Given that transport costs in the case of physical delivery of the underlying commodity are much higher for the U.S. futures contract (the delivery points are either in the U.S. or in Europe) relative to the Brazilian futures contract (the delivery point is in São Paulo), this observation is in line with pricing theory of globally traded commodities (see e.g., Protopapadakis and Stoll 1983). However, from mid-2009 onwards the path of the spread displayed unusual dynamics, as it started to narrow considerably and even turned negative in 2011-12. Against the background that transport costs increased drastically over the same period due to sharp increases in oil prices, this downward trend in the spread is somewhat contrary to expectations.

[FIGURE 3 about here]

The historically unusual downward trend therefore led market participants to expect that Brazilian futures prices will decrease again relative to U.S. prices in the future to restore the historically normal relationship. A relative decrease in Brazilian futures prices is equivalent to a relative strengthening of the Brazilian basis vis-à-vis the U.S. basis, resulting in a higher basis risk for long-hedgers in the Brazilian futures market. Since non-resident investors are predominantly long hedgers as shown by the data in Figure 1(b), the Brazilian futures market became unattractive to them. As a consequence, foreign hedgers decreased their trading activity in the BM\&F Bovespa contract and chose to use the ICE contract for their hedging operations. Foreign investors resumed their activity when the historically normal spread between Brazilian and U.S. futures prices was re-established in mid-2012.

\footnotetext{
${ }^{7}$ As highlighted in ICE (2012), the spread between the ICE 'Coffee C' futures contract and the BM\&F Bovespa Arabica contract is actively monitored by traders. See also Morgan et al. (1999), who emphasize that the basis risk is an influential factor in the hedging decisions of foreign commodity traders.
} 


\section{Econometric Methodology}

The aim of this study is to examine price and volatility dependencies between Brazilian spot/futures markets for Arabica coffee and the U.S. global benchmark futures market. To this end, we employ a trivariate vector error correction model (VECM) with GARCH errors. ${ }^{8}$ The mean equations are specified as follows:

$$
\Delta P_{t}=\mu+\sum_{k=1}^{p} \beta_{k} \Delta P_{t-k}+\alpha E C_{t-1}+\varepsilon_{t}
$$

where $\Delta P_{t}=\left(\Delta p_{1, t}, \Delta p_{2, t}, \Delta p_{3, t}\right)^{\prime}$ constitutes a vector of log-returns of U.S. futures prices, Brazilian futures prices and Brazilian spot prices, respectively. The constant is given by $\mu=\left(\mu_{1}, \mu_{2}, \mu_{3}\right)^{\prime}$. Matrix $\beta_{k}$ is of dimension $3 \times 3$ and captures the impact of the $k-t h$ lag of returns, $\Delta P_{t-k}$, on current returns, $\Delta P_{t}$. Consequently, the off-diagonal elements of $\beta_{k}$ signal whether there are spillovers-in-mean between the three variables in question. The error correction coefficients in the $3 \times 2$ matrix, $\alpha$, indicate the speed of adjustment towards the long-run equilibrium in response to short-run deviations of the system. The corresponding vector of lagged error correction terms, $E C_{t-1}=\left(e c_{1, t-1}, e c_{2, t-1}\right)^{\prime}$, includes the cointegrating equations defined as:

$$
\begin{aligned}
& e c_{1, t}=p_{1, t}-p_{3, t}, \\
& e c_{2, t}=p_{1, t}-p_{2, t},
\end{aligned}
$$

where $p_{1, t}, p_{2, t}$, and $p_{3, t}$ are the log-levels of U.S. futures prices, Brazilian futures prices and Brazilian spot prices, respectively. ${ }^{9}$

We further assume that the VECM residuals $\varepsilon_{t}=\left(\varepsilon_{1, t}, \varepsilon_{2, t}, \varepsilon_{3, t}\right)^{\prime}$ have a time-varying con-

\footnotetext{
${ }^{8}$ The VECM-GARCH framework has been used in several studies to examine the dynamics of futures and spot prices of the same asset, e.g., Brooks et al. (2002), Liu and An (2011) and Avino et al. (2015).

${ }^{9}$ As a robustness check, we also implemented a VECM which includes estimated error correction terms such that $e c_{1, t}=p_{1, t}-\phi_{11}-\phi_{21} p_{3, t}$ and $e c_{2, t}=p_{1, t}-\phi_{12}-\phi_{22} p_{2, t}$. The results are qualitatively similar to those reported in this paper and are available upon request.
} 
ditional covariance matrix $H_{t}$ defined as:

$$
H_{t}=\left[\begin{array}{ccc}
h_{11, t} & h_{12, t} & h_{13, t} \\
h_{21, t} & h_{22, t} & h_{23, t} \\
h_{31, t} & h_{32, t} & h_{33 t}
\end{array}\right],
$$

We apply the multivariate GARCH(1,1)-BEKK representation proposed by Engle and Kroner $(1995)$ to model the conditional variance $H_{t}$. Accordingly, $H_{t}$ takes the following form:

$$
H_{t}=C C^{\prime}+A^{\prime} \varepsilon_{t-1} \varepsilon_{t-1}^{\prime} A+B^{\prime} H_{t-1} B
$$

where $\mathrm{C}$ is lower triangular and $A$ and $B$ are $3 \times 3$ coefficient matrices. Eq. (5) states that the dynamic process of current volatility $\left(H_{t}\right)$ is a function of its own past values $\left(H_{t-1}\right)$ and past values of squared innovations $\left(\varepsilon_{t-1} \varepsilon_{t-1}^{\prime}\right)$. The unrestricted off-diagonal elements of the matrices $A$ and $B$ allow for cross-market influences between conditional variances. By construction, this specification guarantees the positive definiteness of $H_{t}$. In matrix notation, Eq. (5) becomes:

$$
\begin{aligned}
H_{t}=C C^{\prime}+ & {\left[\begin{array}{lll}
a_{11} & a_{12} & a_{13} \\
a_{21} & a_{22} & a_{23} \\
a_{31} & a_{32} & a_{33}
\end{array}\right]^{\prime}\left[\begin{array}{ccc}
e_{1, t-1}^{2} & e_{1, t-1} e_{2, t-1} & e_{1, t-1} e_{3, t-1} \\
e_{2, t-1} e_{1, t-1} & e_{2, t-1}^{2} & e_{2, t-1} e_{3, t-1} \\
e_{3, t-1} e_{1, t-1} & e_{3, t-1} e_{2, t-1} & e_{3, t-1}^{2}
\end{array}\right]\left[\begin{array}{lll}
a_{11} & a_{12} & a_{13} \\
a_{21} & a_{22} & a_{23} \\
a_{31} & a_{32} & a_{33}
\end{array}\right] } \\
+ & {\left[\begin{array}{lll}
b_{11} & b_{12} & b_{13} \\
b_{21} & b_{22} & b_{23} \\
b_{31} & b_{32} & b_{33}
\end{array}\right]^{\prime} H_{t-1}\left[\begin{array}{lll}
b_{11} & b_{12} & b_{13} \\
b_{21} & b_{22} & b_{23} \\
b_{31} & b_{32} & b_{33}
\end{array}\right] . }
\end{aligned}
$$

This model framework permits us to analyze the response of conditional volatilities in the Brazilian futures and spot markets to innovations ("news") in the U.S. futures market and vice versa. Our focus is therefore on the "cross-border" spillovers from the U.S. futures market to Brazilian futures and spot markets $\left(a_{12}\right.$ and $\left.a_{13}\right)$ and on the spillovers from Brazilian markets to the U.S. market $\left(a_{21}\right.$ and $\left.a_{31}\right)$. We also consider the corresponding off-diagonal 
parameters in matrix $B$, which measure the degree of cross-market volatility persistence.

Since we are not only interested in uncovering volatility linkages over the whole sample period, but we also aim to test whether these linkages changed during the prolonged boom period between 2010 and 2012, we modify our baseline BEKK-GARCH model by including a dummy variable $D$ in Eq. (6). This specification allows for shifts in the cross-border spillover parameters during this specific period. The coefficient matrices $A$ and $B$ then take the following form:

$$
A=\left[\begin{array}{ccc}
a_{11} & a_{12}+a_{12 d} \cdot D & a_{13}+a_{13 d} \cdot D \\
a_{21}+a_{21 d} \cdot D & a_{22} & a_{23} \\
a_{31}+a_{31 d} \cdot D & a_{32} & a_{33}
\end{array}\right]
$$

and

$$
B=\left[\begin{array}{ccc}
b_{11} & b_{12}+b_{12 d} \cdot D & b_{13}+b_{13 d} \cdot D \\
b_{21}+b_{21 d} \cdot D & b_{22} & b_{23} \\
b_{31}+b_{31 d} \cdot D & b_{32} & b_{33}
\end{array}\right]
$$

where $D$ is equal to one during the boom period, and zero otherwise. We apply the Bai and Perron $(1998,2003)$ structural break test to identify the start and end date of the boom period. The test results for the series of Brazilian futures prices suggest a break on June 16, 2010 and a break on April 25, 2012. Consequently, we set the dummy equal to one for the period between both break dates.

The shift-dummy approach allows us to derive implications regarding the relative importance of local and global market information for volatility processes during the boom episode. ${ }^{10}$ Specifically, we test two sets of null hypotheses:

(i) No shift in spillovers from U.S. to Brazilian markets during the boom period, neither from the U.S. to the Brazilian futures market $\left(H_{0}: a_{12 d}=b_{12 d}=0\right)$ nor from the U.S. to Brazilian spot markets $\left(H_{0}: a_{13 d}=b_{13 d}=0\right)$. Rejecting one or both null hypotheses would indicate that volatility shocks from the global benchmark became more important for the

\footnotetext{
${ }^{10} \mathrm{We}$ abstract from the question whether a shift in any of the spillover parameters can be interpreted as evidence of contagion effects (see e.g., Beirne et al. 2013). We rather view the shift-dummy parameters as indicators for a change in the magnitude and direction of information flows across markets, which is consistent with the notion that volatility spillovers reflect information transmission (Chan et al. 1991).
} 
volatility processes of local Brazilian markets during the boom period.

(ii) No shift in spillovers from Brazilian markets to the U.S. market during the boom period, neither from the Brazilian futures market to the U.S. $\left(H_{0}: a_{21 d}=b_{21 d}=0\right)$ nor from the Brazilian spot markets to the U.S. $\left(H_{0}: a_{31 d}=b_{31 d}=0\right)$. Rejecting one or both null hypotheses would suggest that volatility shocks from local coffee markets had a larger impact on world market volatility dynamics during the boom episode relative to the remainder of the sample period.

We estimate the model by maximum likelihood using the Broyden-Fletcher-GoldfarbShanno (BFGS) algorithm. To account for the excess kurtosis ("fat tails") that we detect in our data, we implement the maximum likelihood estimation under the assumption that conditional errors, $\varepsilon_{t}$, follow a Student's $t$-distribution with $\nu$ degrees of freedom, which offers a better fit to the data than the Normal distribution (Bollerslev 1987). ${ }^{11}$ We select the optimal number of lags $p$ in Eq. (1) in such a way that no serial correlation and no GARCH effects remain in the model's standardized residuals.

\section{Data Description}

Our analysis is based on daily data for three time series of Arabica coffee prices: (i) U.S. futures prices, (ii) Brazilian futures prices and (iii) Brazilian spot prices. Our sample period runs from January 2, 2003 until July 2, 2015. The data source for all prices is Thomson Reuters Datastream.

Table 1 lists some details regarding U.S. and Brazilian futures contract specifications as well as spot market characteristics. For U.S. data we rely on prices for the Arabica 'Coffee C' futures contract traded at the ICE in New York. ${ }^{12}$ The 'Coffee C' contract is the global benchmark for Arabica coffee and hence reflects the world market situation (ICE 2012). It is

\footnotetext{
${ }^{11}$ It is well documented that distributions of commodity returns are typically leptokurtic and thus nonNormal (Baillie and Myers 1991).

${ }^{12}$ Until January 2007 the 'Coffee C' futures contract was traded at the Coffee, Sugar and Cocoa Exchange (CSCE) in New York. As a consequence of the merger between CSCE and ICE, the trading of the contract was relocated to the ICE.
} 
designed to price physical delivery of green Arabica beans from one of 20 producing countries to licensed warehouses in the U.S. and Europe.

[TABLE 1 about here]

Brazilian futures prices refer to the Arabica coffee contract traded at the BM\&F Bovespa in São Paulo. The contract's average daily trading volume over our sample period amounts to 1590 contracts, which represents merely eight percent of trading volume in the corresponding ICE contract, but it is still considerably more than the trading activity in the Arabica coffee contract traded at the New York Mercantile Exchange (NYMEX). ${ }^{13}$

Our data of Brazilian spot prices consist of a daily price index summarizing the cash market situation in the most important trading areas in Brazil. The index is compiled by ESALQ (Centro de Estudos Avançados em Economia Aplicada), a recognized research center at the University of São Paulo. It reflects average prices for trading in local cash markets on business days between 2.00 and $5.00 \mathrm{pm}$. Local prices included in the index are adjusted for payment terms and transport costs to São Paulo and then converted to U.S. dollar. Consequently, the ESALQ spot price index corresponds to the average cash price (in U.S. dollar) of the product for delivery to São Paulo.

Futures data corresponds to settlement prices that are determined nearly at the same time for both contracts, namely between 2.23 and 2.25 p.m. at the ICE and between 2.25 and 2.35 p.m. (both in São Paulo time) at the BM\&F Bovespa. Hence, there is virtually no issue with regards to asynchronous price data in the two futures markets. ${ }^{14}$ We use futures price observations from the most nearby contract, as this is typically the most actively traded one. To obtain a continuous time series we roll over to the next nearby contract on the first day of the delivery month. Since the price quotation in the U.S. (cents per pound) differs from that in the two Brazilian markets (U.S. dollar per $60 \mathrm{~kg}$ ), we transform the U.S. price data

\footnotetext{
${ }^{13}$ These three futures contracts are the only ones worldwide that are offered for the coffee bean of type Arabica. A fourth contract traded at the Tokyo Grain Exchange was delisted in February 2013.

${ }^{14}$ The fact that cash markets close later than the two futures markets may give rise to a potential bias, which should be borne in mind when interpreting the results.
} 
such that each time series is expressed in U.S. dollar per 60 kilogram bag.

For our econometric analysis we calculate daily percentage returns, $100 * \log \left(P_{t} / P_{t-1}\right)$, where $\log$ denotes the natural logarithm and $P_{t}$ the corresponding time series in levels. Panel A of Table 2 reports descriptive statistics of our data. The means of all returns are slightly positive and exhibit similar standard deviations. The statistics on skewness show that the distributions of both U.S. and Brazilian futures returns have positive skew, while the distribution of spot returns has negative skew. Furthermore, the excess kurtosis is near two for all three returns series, which clearly exceeds the value of zero for a Normal distribution. ${ }^{15}$ A formal test for an excess kurtosis of zero is rejected for all three series, thereby indicating a fat-tailed distribution. Evidence in favor of a non-Normal distribution is further provided by the results of the Jarque-Bera test in the second last column of Panel A, which strongly refutes the null hypothesis of a Normal distribution. Finally, LM-ARCH tests with 6 lags of the residuals from the preliminary regression reject the null hypothesis of no ARCH effects in the data.

[TABLE 2 about here]

Next, we examine the stationarity properties of each time series by applying the AugmentedDickey-Fuller (ADF) test and the Kwiatkowski-Philips-Schmidt-Shin (KPSS) test. While the ADF test assumes the null hypothesis that there is a unit root in the time series, the KPSS test states the opposite null hypothesis, namely that the time series is stationary. Our test results in Panel B of Table 2 unequivocally indicate non-stationarity in levels and stationarity in first differences, leading us to conclude that all time series in our data set are $I(1)$.

As the last step of our preliminary data analysis we conduct the Johansen trace test (Johansen 1991, 1995) to test for cointegration. We identify the optimal lag length for the test equations on the basis of the Akaike Information Criterion. The results are summarized in Panel $\mathrm{C}$ of Table 2 and suggest that the null hypothesis of zero cointegrating vectors

\footnotetext{
${ }^{15}$ The statistic on excess kurtosis shows the fourth moment of the distribution minus three. It follows that it has an expected value of zero in the case of a Normal distribution.
} 
$\left(r_{0}=0\right)$ as well as that of one cointegrating vector $\left(r_{0}=1\right)$ can be rejected at the 1 percent level, whereas the null of two cointegrating vectors $\left(r_{0}=2\right)$ cannot be rejected. The Johansen trace test thus indicates the presence of two cointegrating relations between the three Arabica coffee time series. ${ }^{16}$ Taken together, the above results support our econometric approach to use a VECM-GARCH specification with $t$-distributed errors as outlined in Section 3.

\section{$5 \quad$ Empirical Results}

\subsection{Baseline Results}

Estimation results for the baseline BEKK-GARCH(1,1) model are presented in Tables 3 and 4. We choose a parsimonious model and include two lags of each variable in the mean equations. Higher order models are not supported by Schwarz's Bayesian Information Criterion. Diagnostic tests on the standardized residuals are reported in Panel C of Table 3 and confirm the adequacy of our model. The multivariate $Q$-statistic (Hosking 1981) and the multivariate $\mathrm{ARCH}$ test (Hacker and Hatemi 2005) for 6 and 12 lags of the standardized residuals suggest that the null hypothesis of no serial correlation and of no ARCH effects, respectively, cannot be rejected. Hence, our specification is appropriate to capture the conditional heteroskedasticity and serial correlation in our data.

The estimated degrees of freedom parameter of the Student's $t$-distribution is $\hat{\nu}=4.42$, which implies a very leptokurtic distribution of residuals. ${ }^{17}$ Moreover, we obtain further evidence in favor of our distributional assumption by comparing the value of the log-likelihood function for the model with $t$-errors to the likelihood for a model with normally distributed errors, as the former produces a considerably higher value. As a final check for model adequacy we compute the eigenvalues of $A \otimes A+B \otimes B$, where $\otimes$ is the Kronecker product, to verify that our parameterization guarantees covariance stationarity. This condition is

\footnotetext{
${ }^{16}$ These findings are in line with other studies testing for cointegration among commodities that are traded in internationally separated markets (e.g., Fung et al. 2010; Han et al. 2013).

${ }^{17}$ Note that a value for $\hat{\nu}$ close to 2 indicates a very high excess kurtosis in the residuals. The $t$-distribution approaches the Normal distribution as the degrees of freedom parameter increases, $\hat{\nu} \rightarrow \infty$ (Bollerslev 1987).
} 
satisfied since all eigenvalues (not reported) are smaller than one in modulus.

[TABLE 3 about here]

Table 3 summarizes the parameter estimates for the three conditional mean equations. Focusing on the parameters of the lagged returns in the matrices $\beta_{1}$ and $\beta_{2}$, it is shown that the two futures markets strongly influence each other as indicated by the significant cross-market coefficients for both lags $\left(\beta_{12,1}, \beta_{12,2}\right.$ and $\beta_{21,1}, \beta_{21,2}$, respectively). Hence, there is a strong bi-directional causality in returns between both futures markets. With regards to spot markets we find that it has an immediate impact on U.S. prices, as given by the significant first lag of spot returns in the U.S. futures market equation $\left(\beta_{13,1}\right)$. The impact of the U.S. futures market on spot returns, by contrast, only shows up at the second lag, $\beta_{31,2}$, suggesting that spot prices react with a delay to foreign market information. Finally, all error correction coefficients in $\alpha$ are significant, either at the $1 \%$ or $5 \%$ level. This indicates that all three markets react to deviations from the long-run equilibrium and that this reaction occurs very fast, since prices adjust within one trading day to correct any disparity between the three markets.

In Panel B of Table 3 we further address the question of causality between returns. We conduct Wald tests on the two lags of cross-market returns in each of the three mean equations. The results confirm that the markets strongly influence each other, since we can reject the null hypothesis of no causality between returns in all cases.

Turning to the parameter estimates of the conditional variance equations in Panel A of Table 4, we observe significant "own-market" coefficients of lagged innovations $\left(a_{11}, a_{22}, a_{33}\right)$ and volatility $\left(b_{11}, b_{22}, b_{33}\right)$ in each market, reflecting a high degree of GARCH-effects in our data. The values of the own-market volatility parameters are in the range from 0.87 to 0.97, which indicates substantial volatility persistence. We also find strong evidence of bidirectional volatility transmission between the U.S. and the Brazilian futures market, since the parameters $a_{12}$ and $a_{21}$ are both significant at the $1 \%$ level. The strong volatility linkages 
between the two futures markets also show up in the corresponding off-diagonal elements of the $B$ matrix $\left(b_{12}\right.$ and $\left.b_{21}\right)$.

[TABLE 4 about here]

The volatility linkages of the spot markets turn out to be weaker. Based on the parameter estimates in the $A$ matrix, spot market volatility is neither influenced by shocks from any of the futures markets nor do shocks from spot markets significantly influence volatility in the two futures markets. The relevant parameters in the $B$ matrix show some degree of volatility interaction between the U.S. futures market and the spot markets ( $b_{13}$ and $b_{31}$ are statistically different from zero) and volatility transmission from the Brazilian futures market to the spot markets $\left(b_{23}\right.$ is significant). We further test for volatility linkages between the three markets by means of Wald tests on each pair of spillover parameters. The test statistics shown in Panel B of Table 4 suggest that there is bi-directional volatility transmission between both futures markets, whereas spot markets are merely a receiver and not a transmitter of volatility.

Our results from the baseline GARCH model allow several conclusions. First, there is a high degree of interdependence in price and volatility dynamics between the BM\&F Bovespa futures contract for Arabica coffee and the global benchmark, the ICE 'Coffee C' contract. This implies that information is rapidly exchanged between both trading places. In the light of investor data revealing a strong activity of foreign traders in the Brazilian futures market over most of the sample period, this finding corroborates the notion that emerging markets with a large extent of foreign investments can process global price information very quickly (Bae et al. 2012).

Second, the finding that the Brazilian futures market substantially influences the ICE market suggests a major role of the BM\&F Bovespa in the global price formation process of Arabica coffee. The global importance of the Brazilian derivatives exchange thus corresponds directly to Brazil's status as the world's largest producer of Arabica coffee. Our evidence 
is consistent with the related literature documenting the remarkably strong influence of emerging economies' futures markets, notably in China, on price and volatility dynamics in commodity markets of mature economies (e.g., Fung et al. 2010; Liu and An 2011; Han et al. 2013; Yin and Han 2013).

Third, the cross-market dependencies of spot markets are relatively weaker, especially in terms of volatility linkages. While this implies adverse effects for the spot markets' informational efficiency, it may also have benefits for spot market participants in the sense that excessive short-term volatility spikes in futures markets are not immediately transmitted to physical markets.

\subsection{Volatility Spillover Dynamics in the Large Boom Period}

To analyze whether the transmission of volatility spillovers across borders changed during the price spikes between 2010 and 2012, we modify our baseline BEKK-GARCH model by including a dummy variable that accounts for shifts in the cross-border spillover parameters during this specific period. This permits us to derive conclusions regarding the importance of global relative to local news for the volatility processes during the boom period. As discussed in Section 2, this turbulent period was associated with very little participation by foreign investors in the Brazilian futures market due to increased basis risk faced by hedgers. On average, less than 5 percent of positions were held by foreign investors in this period. This contrasts sharply with foreign traders' average share of 23 percent over the remainder of the sample.

Panel A of Table 5 summarizes the parameter estimates for all cross-border spillover coefficients including the shift-dummy parameters for our modified BEKK-GARCH model in Eqs. (7) and (8). ${ }^{18}$ The shift dummy parameters for the spillover effects from the U.S. futures to the Brazilian futures market $\left(a_{12 d}\right.$ and $\left.b_{12 d}\right)$ and from the U.S. futures to the Brazilian spot markets $\left(a_{13 d}\right.$ and $\left.b_{13 d}\right)$ are insignificant, indicating that spillovers from the U.S. to Brazilian

\footnotetext{
${ }^{18}$ Residual diagnostics in Panel $\mathrm{C}$ of Table 5 confirm model adequacy.
} 
markets remained unchanged during the 2010-2012 boom period. By contrast, the shift dummy coefficients for the spillovers from the Brazilian futures market to the U.S. $\left(a_{21 d}\right.$ and $\left.b_{21 d}\right)$ are significant, thereby suggesting a change in the volatility transmission mechanism. Moreover, the sum of regular and shift dummy coefficients $\left(a_{21}+a_{21 d}\right.$ and $\left.b_{21}+b_{21 d}\right)$ is larger in absolute terms than the individual point estimates, which shows that spillovers increased during the period of price spikes. There is also some evidence that spillovers from the spot markets to the U.S. market increased as suggested by the significant shift parameter $a_{31 d}$.

[TABLE 5 about here]

Our results are further supported by Wald tests on each pair of shift dummy parameters reported in Panel B. The null hypothesis of no shift in volatility spillovers is rejected only in the case of volatility spillovers from the Brazilian futures market to the U.S. futures market $\left(a_{21 d}=b_{21 d}=0\right)$.

Taken together, we find robust evidence for a sizeable increase in spillover effects from the Brazilian futures market to the U.S. market during our sample's most pronounced boom period in Arabica coffee prices. However, we do not identify such an increase in spillovers operating in the opposite direction (i.e., from U.S. to Brazil). The latter finding of a limited effect of foreign price shocks on local markets' volatility in Brazil is consistent with the fact that there was very little trading activity by foreign investors in the BM\&F Bovespa contract during this specific period. Our results therefore indicate that global information, which is transmitted through price signals from the world benchmark ICE futures contract, was less important for the synchronized price spikes in Arabica coffee markets between 2010 and 2012. Instead, our findings lend support to the idea that local information on supply and demand factors, which is incorporated in Brazilian futures and spot prices, was more relevant for the volatility dynamics during the large price boom. 


\section{Conclusions}

This paper assesses to which extent the Brazilian futures exchange, BM\&F Bovespa, contributes to the global transmission of information in Arabica coffee markets. Our study serves to deepen the understanding of the role of emerging economies in the global price formation process of commodities. We focus our analysis on Brazil as it is the world's largest producer of Arabica coffee and because it has an active domestic futures market for this commodity.

Using a multivariate BEKK-GARCH model we analyze price and volatility spillovers between the BM\&F Bovespa futures market for Arabica coffee and the U.S. global benchmark ICE, the 'Coffee C' futures market. Moreover, our model also considers physical markets by including data from local Brazilian spot markets. Our results show that there are strong bi-directional spillovers in mean and volatility among the two futures markets, reflecting a high degree of interdependence between local and global futures prices. In addition, we find that local spot markets receive informational spillovers from both the foreign and the domestic futures market.

The second part of our analysis focuses on the cross-border volatility transmission pattern during the large boom in Arabica coffee prices between 2010 and 2012. Our estimates suggest that volatility spillovers from the BM\&F Bovespa to the ICE became stronger during the boom period, whereas spillovers originating from the ICE futures market remained unchanged. Consequently, we do not find evidence for the argument that the price spikes in Arabica coffee markets were induced by speculative trading in the U.S. ICE market. The increased importance of shocks from the BM\&F Bovespa rather underscores that information from local traders in Brazilian markets was more relevant for volatility dynamics during the price boom. This is further supported by investor data showing that trading in the Brazilian futures market was heavily dominated by local investors after foreign traders largely withdrew from the market during the price spikes.

Our empirical results have important regulatory implications. In particular, this study 
serves to attenuate concerns among regulators who challenge the benefits of liberalizing commodity futures markets in emerging economies. Our findings rather suggest that opening up futures markets helps to increase the influence of emerging economies on the global price formation process of commodities. In addition, we do not find evidence for the argument that foreign investors contribute to price spikes in commodity futures markets. We therefore conclude that the regulatory framework of the BM\&F Bovespa in Brazil may be seen as a role model for other emerging economies such as China and India, where commodity trading is still highly regulated. 


\section{References}

Adämmer, P., Bohl, M.T., and von Ledebur, O. (2016). Dynamics Between North American and European Agricultural Futures Prices During Turmoil and Financialization, Bulletin of Economic Research (forthcoming).

Antoniou, A., and Holmes, P. (1995). Futures Trading, Information and Spot Price Volatility: Evidence for the FTSE-100 Stock Index Futures Contract Using GARCH, Journal of Banking and Finance, Vol. 19(1), 117-129.

Avino, D., Lazar, E., and Varotto, S. (2015). Time Varying Price Discovery, Economics Letters, Vol. 126, 18-21.

Bae, K.H., Ozoguz, A., Tan, H., and Wirjanto, T.S. (2012). Do Foreigners Facilitate Information Transmission in Emerging Markets?, Journal of Financial Economics, Vol. 105(1), 209-227.

Bai, J., and Perron, P. (1998). Estimating and Testing Linear Models with Multiple Structural Changes, Econometrica, Vol. 66(1), 47-78.

Bai, J., and Perron, P. (2003). Computation and Analysis of Multiple Structural Change Models, Journal of Applied Econometrics, Vol. 18(1), 1-22.

Baillie, R.T. and Myers, R.J. (1991). Bivariate Garch Estimation of the Optimal Commodity Futures Hedge, Journal of Applied Econometrics, Vol. 6(2), 109-124.

Beirne, J., Caporale, G.M., Schulze-Ghattas, M., and Spagnolo, N. (2013), Volatility Spillovers and Contagion from Mature to Emerging Stock Markets, Review of International Economics, Vol. 21(5), 1060-1075.

Black, F. (1976). The Pricing of Commodity Contracts. Journal of Financial Economics, Vol. 3(1), 167-179.

Bollerslev, T. (1987). A Conditionally Heteroskedastic Time Series Model for Speculative Prices and Rates of Return, Review of Economics and Statistics, Vol. 69(3), 542-547.

Booth, G.G., and Ciner, C. (1997). International Transmission of Information in Corn Futures Markets, Journal of Multinational Financial Management, Vol. 7(3), 175-187. 
Brooks, C., Henry, O.T., and Persand, G. (2002). The Effect of Asymmetries on Optimal Hedge Ratios, The Journal of Business, Vol. 75(2), 333-352.

Chan, K., Chan, K.C., and Karolyi, A.G. (1991). Intraday Volatility in the Stock Index and Stock Index Futures Markets, Review of Financial Studies, Vol. 4(4), 657-684.

Chicago Board of Trade (CBOT) (2004). Understanding Basis, Chicago: Chicago Board of Trade.

Choe, H., Kho, B., Stulz, R.M. (1999). Do Foreign Investors Destabilize Stock Markets? The Korean Experience in 1997, Journal of Financial Economics, Vol. 54(2), 227-264. De Mello, P.C. (2006). Trading Futures Contracts in A Developing Country: The Economic History of Brazil's BMSP, Working Paper Presented at the XIV International Economic History Congress in Helsinki.

Engle, R., and Kroner, K. (1995). Multivariate Simultaneous Generalized ARCH, Econometric Theory, Vol. 11(1), 122-150.

Food and Agriculture Organization of the United Nations (FAO) (2011). Price Volatility in Food and Agricultural Markets: Policy Responses. Policy Report Including Contributions by FAO, IFAD, IMF, OECD, UNCTAD, WFP, the World Bank, the WTO, IFPRI and the UN HLTF, June.

Futures Industry Association (FIA) (2006). FIA Annual Volume Survey 2005, Futures Industry, March.

Futures Industry Association (FIA) (2016). FIA Annual Volume Survey 2015, Futures Industry, March.

Fung, H.G., Liu, Q., and Tse, Y. (2010). The Information Flow and Market Efficiency Between the U.S. and Chinese Aluminium and Copper Futures Markets, Journal of Futures Markets, Vol. 30(12), 1192-1209.

Garcia, G., and Sanders, D.R. (1996). Ex Ante Basis Risk in the Live Hog Futures Contract: Has Hedgers' Risk Increased?, Journal of Futures Markets, Vol. 16(4), 421-440.

Ghysels, E., and Seon, J. (2005). The Asian Financial Crisis: The Role of Derivative Securities Trading and Foreign Investors in Korea, Journal of International Money and 
Finance, Vol. 24, 607-630.

Hacker, R., and Hatemi, A. (2005). A Test for Multivariate ARCH Effects, Applied Economics Letters, Vol. 12(7), 411-417.

Han, L., Liang, R., and Tang, K. (2013). Cross-Market Soybean Futures Price Discovery: Does the Dalian Commodity Exchange Affect the Chicago Board of Trade, Quantitative Finance, Vol. 13(4), 613-626.

Hernandez, M.A., Ibarra, R., and Trupkin, D.R. (2014). How Far Do Shocks Move Across Borders? Examining Volatility Transmission in Major Agricultural Futures Markets, European Review of Agricultural Economics, Vol. 41(2), 301-325.

Hosking, J. (1981). Equivalent Forms of the Multivariate Portmanteau Statistic, Journal of the Royal Statistical Society, Series B, Vol. 43, 261-62.

Hua, R., and Chen, B. (2007). International Linkages of the Chinese Futures Markets, Applied Financial Economics, Vol. 17(16), 1275-1287.

International Continental Exchange (ICE) (2012). ICE Coffee Brochure, link: https: \\www.theice.com $\backslash$ publicdocs $\backslash$ ICE_Coffee_Brochure.pdf.

Johansen, S. (1991). Estimation and Hypothesis Testing of Cointegration Vectors in Gaussian Vector Autoregressive Models, Econometrica Vol. 59(6), 1551-1580.

Johansen, S. (1995). Likelihood-based Inference in Cointegrated Vector Autoregressive Models, Oxford University Press: Oxford.

Kaminsky, G., Lyons, R.K., Schmukler, S.L. (2004). Managers, Investors, and Crises: Mutual Fund Strategies in Emerging Markets, Journal of International Economics, Vol. 64(1). 113-134.

Kuserk, G. (2010). Speculation and Hedging, in: Kolb, R.W., and Overdahl, J.A. (ed.), Financial Derivatives - Pricing and Risk Management, John Wiley: Hoboken.

Leuthold, R.M. (1994). Evaluating Futures Exchanges in Liberalising Economies, Development Policy Review, Vol. 12(2), 149-163.

Lien, D., and Zhang, M. (2008). A Survey of Emerging Derivatives Markets, Emerging Markets Finance and Trade, Vol. 44(2), 39-69. 
Liu, Q., and An, Y. (2011). Information Transmission in Informationally Linked Markets: Evidence from US and Chinese Commodity Futures Markets, Journal of International Money and Finance, Vol. 30(5), 778-795.

MacKinnon, J.G., Haug, A.A., and Michelis, L. (1999). Numerical Distribution Functions of Likelihood Ratio Tests for Cointegration, Journal of Applied Econometrics, Vol. 14(5), 563-577.

Morgan, C.W., Rayner, A.J., and Vaillant, C. (1999). Agricultural Futures Markets in LDCs: A Policy Response to Price Volatility?, Journal of International Development, Vol. 11(6), 893-910.

Peck, A.E. (1976). Futures Markets, Supply Response, and Price Stability, Quarterly Journal of Economics, Vol. 90(3), 407-423.

Protopapadakis, A., and Stoll, H.R. (1983). Spot and Futures Prices and the Law of One Price, Journal of Finance, Vol. 38(5), 1431-1455.

Tse, Y., and Booth, G.G. (1997). Information Shares in International Oil Futures Markets, International Review of Economics and Finance, Vol. 6(1), 49-56.

United Nations Conference on Trade and Development (UNCTAD) (2009). Development Impacts of Commodity Exchanges in Emerging Markets, United Nations: New York. Webb, R.I, Ryu, D., Ryu, D., and Han, J. (2016). The Price Impact of Futures Trades and their Intraday Seasonality, Emerging Markets Review, Vol. 26, 80-98.

Working, H. (1962). New Concepts Concerning Futures Markets and Prices. American Economic Review 52(3), 431-459.

Yin, L., and Han, L. (2013). Exogenous Shocks and Information Transmission in Global Copper Futures Markets, Journal of Futures Markets, Vol. 33(8), 724-751. 
Figure 1: Participation by Non-Resident Investors in the BM\&F Bovespa Arabica Coffee Futures Market

(a) Aggregated Participation

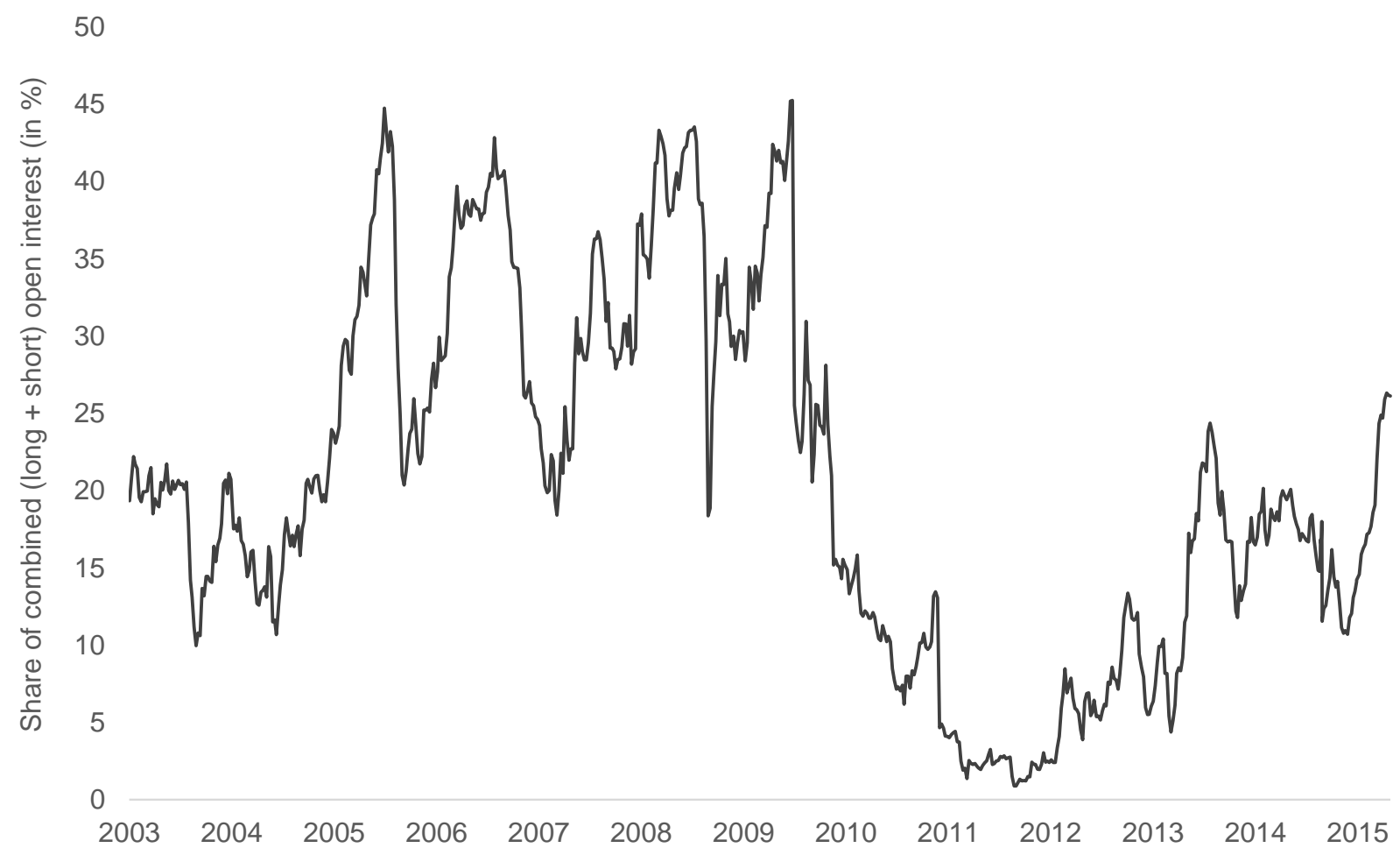

(b) Disaggregated by Long and Short Positions

80

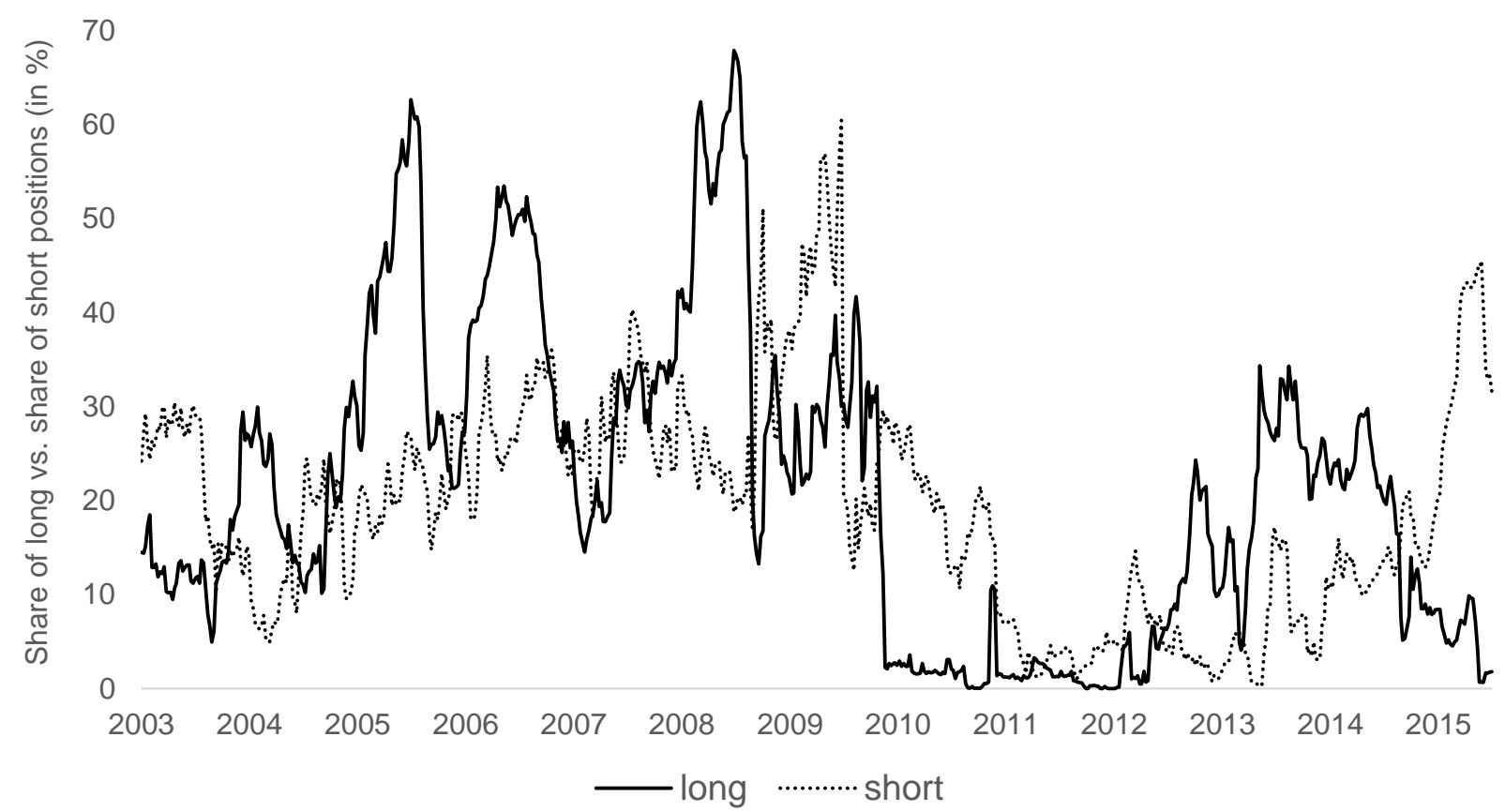

Data source: BM\&F Bovespa. 
Figure 2: Prices of Brazilian and U.S. Coffee Markets

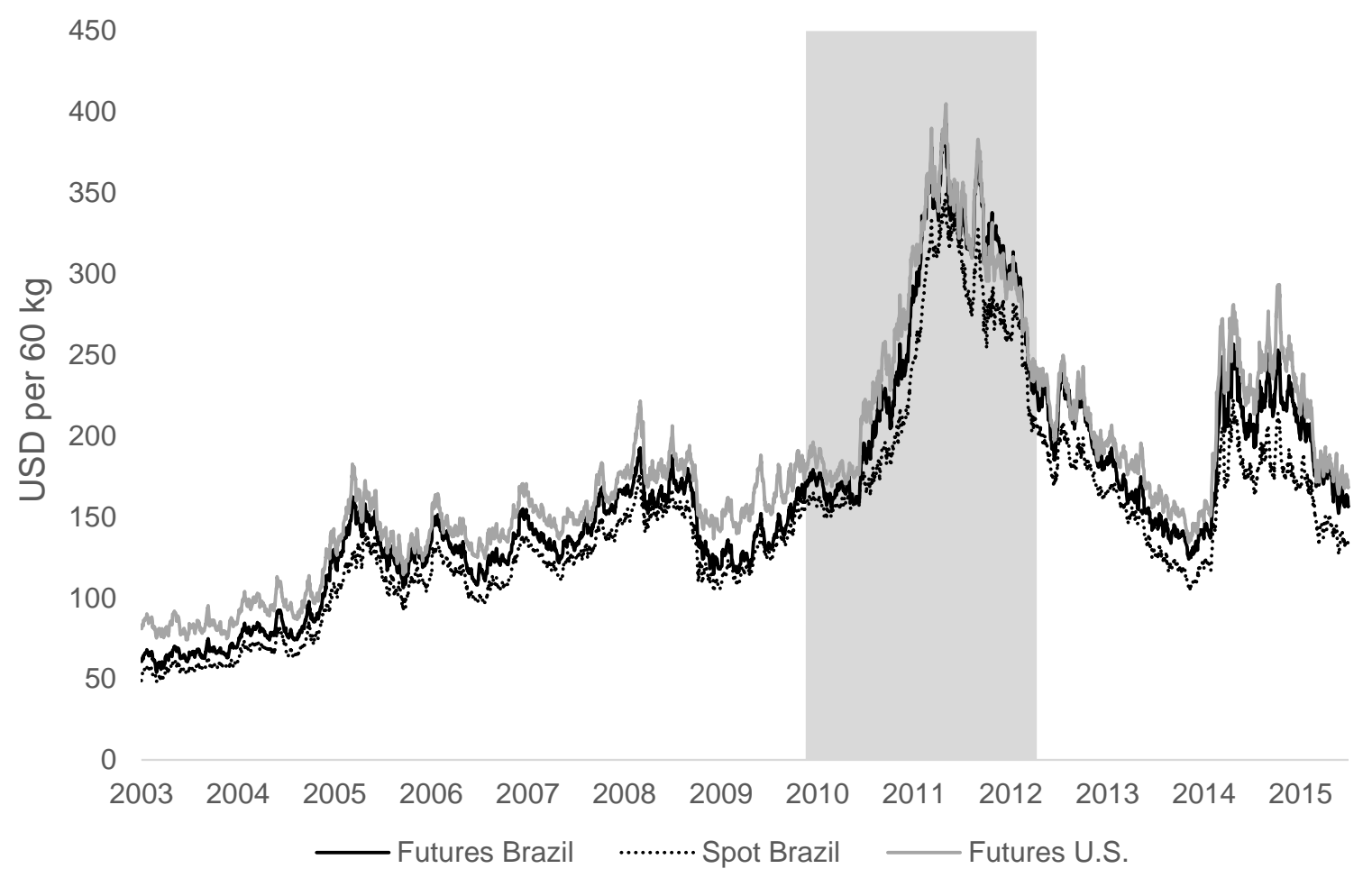

The shaded area indicates the period with the lowest participation by foreign investors in the Brazilian futures market during our sample period. 
Figure 3: Difference between Futures Prices for Arabica Coffee in New York and São Paulo

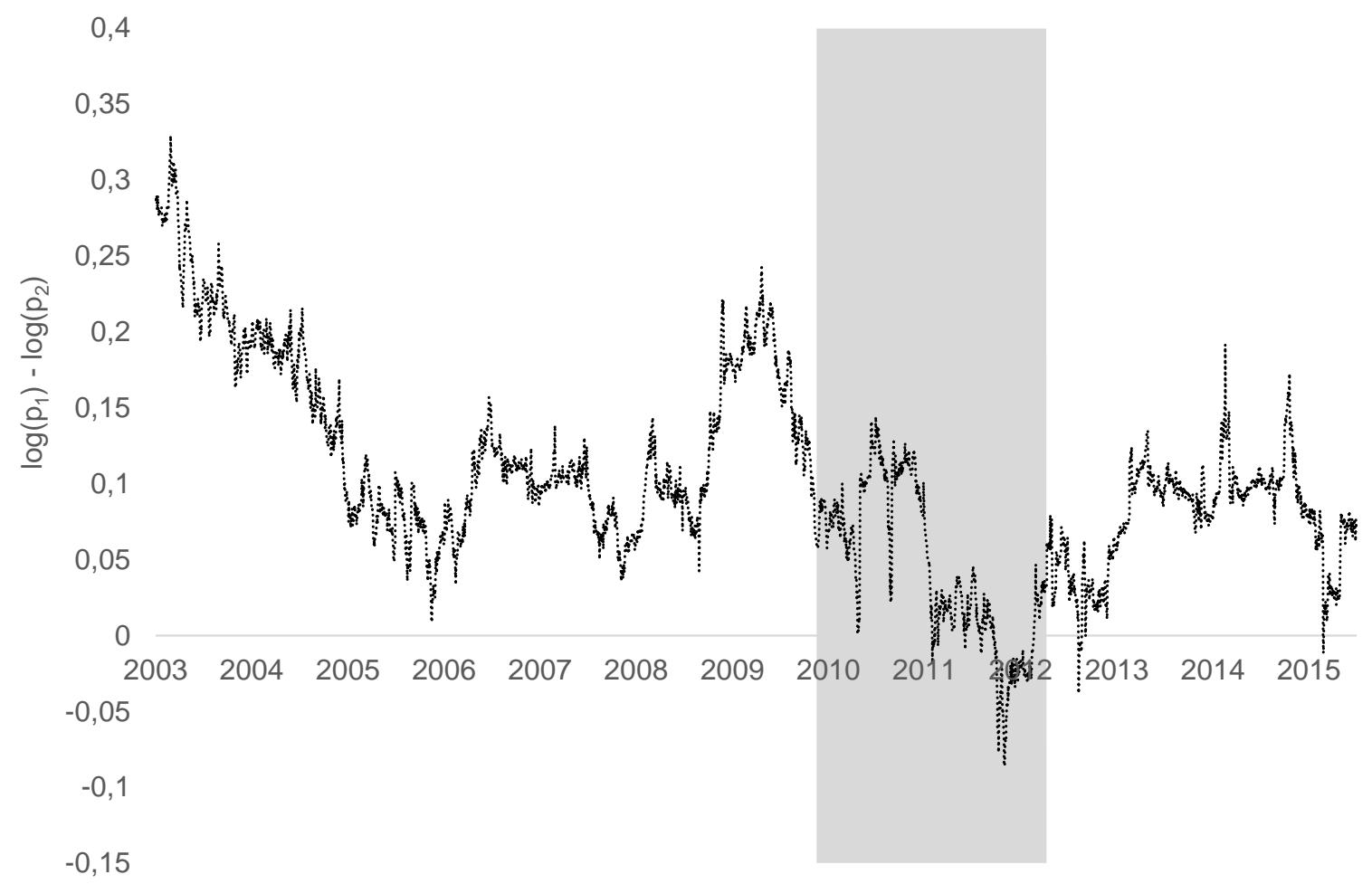

$p_{1}$ and $p_{2}$ denote the prices for Arabica coffee at the futures exchanges in New York and São Paulo, respectively. The shaded area indicates the period with the lowest participation by foreign investors in the Brazilian futures market during our sample period. 
Table 1: Details on Futures Contract Specifications and Spot Market Characteristics

\begin{tabular}{llll}
\hline & U.S. futures & Brazilian futures & Brazilian spot \\
\hline Trading exchange & ICE in New York & $\begin{array}{l}\text { BM\&F Bovespa in São } \\
\text { Paulo }\end{array}$ & Major local trading areas \\
in Brazil
\end{tabular}

Prior to 2007, the U.S. contract was traded at the Coffee, Sugar and Cocoa Exchange (CSCE) in New York. USD denotes U.S. dollar. 
Table 2: Summary Statistics

\begin{tabular}{|c|c|c|c|c|c|c|}
\hline & \multicolumn{6}{|c|}{ Panel A: Descriptive Statistics } \\
\hline & Mean & Std. Dev. & Skewness & Exc. Kurt. & Jarque-Bera & ARCH-LM(6) \\
\hline$\Delta p_{1, t}$ & 0.0241 & 2.1001 & 0.2151 & $1.9828^{* * *}$ & $515.9860^{* * *}$ & $16.936^{* * *}$ \\
\hline$\Delta p_{2, t}$ & 0.0312 & 1.9484 & 0.2628 & $2.0382^{* * *}$ & $555.3197^{* * *}$ & $20.568^{* * *}$ \\
\hline \multirow[t]{3}{*}{$\Delta p_{3, t}$} & 0.0328 & 2.0509 & -0.1844 & $2.1040^{* * *}$ & $571.9140^{* * *}$ & $62.214^{* * *}$ \\
\hline & \multicolumn{6}{|c|}{ Panel B: Unit Root Tests } \\
\hline & $\mathrm{ADF}$ & KPSS & & & $\mathrm{ADF}$ & KPSS \\
\hline \multirow{8}{*}{$\begin{array}{l}p_{1, t} \\
p_{2, t} \\
p_{3, t}\end{array}$} & -2.1607 & $4.3668^{* * *}$ & & $\Delta p_{1, t}$ & $-55.5938^{* * *}$ & 0.1507 \\
\hline & -2.1794 & $4.2662^{* * *}$ & & $\Delta p_{2, t}$ & $-54.4402^{* * *}$ & 0.2236 \\
\hline & -2.3894 & $4.1732^{* * *}$ & & $\Delta p_{3, t}$ & $-56.9238^{* * *}$ & 0.3122 \\
\hline & \multicolumn{6}{|c|}{ Panel C: Johansen Trace Test } \\
\hline & \multicolumn{2}{|c|}{$H_{0}: \mathrm{r}=r_{0}$} & \multicolumn{2}{|c|}{ Trace statistic } & \multicolumn{2}{|c|}{$5 \%$ critical value } \\
\hline & \multicolumn{2}{|c|}{$r_{0}=0$} & \multicolumn{2}{|c|}{$104.3438^{* * *}$} & \multicolumn{2}{|c|}{35.1927} \\
\hline & \multicolumn{2}{|c|}{$r_{0}=1$} & \multicolumn{2}{|c|}{$40.6314^{* * *}$} & \multicolumn{2}{|c|}{25.2618} \\
\hline & \multicolumn{2}{|c|}{$r_{0}=2$} & \multicolumn{2}{|c|}{5.7995} & \multicolumn{2}{|c|}{9.1645} \\
\hline
\end{tabular}

$p_{1, t}, p_{2, t}$, and $p_{3, t}$ are the log-levels of U.S. futures prices, Brazilian futures prices and Brazilian spot prices, respectively, and $\Delta$ represents the difference operator. Panel A shows descriptive statistics for the returns. Panel B reports results of the Augmented-Dickey-Fuller (ADF) test and Kwiatkowski-Philips-Schmidt-Shin (KPSS) test on the log-levels and -returns of our data. We include a constant in each test equation. Panel $\mathrm{C}$ presents the results of the Johansen trace test, where $r$ denotes the cointegrating rank (i.e., the number of cointegrating relations) between the three time series. Critical values are taken from MacKinnon et al. (1999). ${ }^{*},{ }^{* *},{ }^{* * *}$ denote statistical significance at the 10, 5, and 1 percent level, respectively. 
Table 3: Estimation Results of BEKK-GARCH-Model - Mean Equations

$\left[\begin{array}{l}\Delta p_{1, t} \\ \Delta p_{2, t} \\ \Delta p_{3, t}\end{array}\right]=\left[\begin{array}{l}\mu_{1} \\ \mu_{2} \\ \mu_{3}\end{array}\right]+\left[\begin{array}{lll}\beta_{11,1} & \beta_{12,1} & \beta_{13,1} \\ \beta_{21,1} & \beta_{22,1} & \beta_{23,1} \\ \beta_{31,1} & \beta_{32,1} & \beta_{33,1}\end{array}\right]\left[\begin{array}{l}\Delta p_{1, t-1} \\ \Delta p_{2, t-1} \\ \Delta p_{3, t-1}\end{array}\right]+\left[\begin{array}{lll}\beta_{11,2} & \beta_{12,2} & \beta_{13,2} \\ \beta_{21,2} & \beta_{22,2} & \beta_{23,2} \\ \beta_{31,2} & \beta_{32,2} & \beta_{33,2}\end{array}\right]\left[\begin{array}{l}\Delta p_{1, t-2} \\ \Delta p_{2, t-2} \\ \Delta p_{3, t-2}\end{array}\right]+\left[\begin{array}{ll}\alpha_{11} & \alpha_{12} \\ \alpha_{21} & \alpha_{22} \\ \alpha_{31} & \alpha_{32}\end{array}\right]\left[\begin{array}{l}e c_{1, t-1} \\ e c_{2, t-1}\end{array}\right]$

\begin{tabular}{|c|c|c|c|c|c|c|c|c|c|c|c|c|}
\hline \multicolumn{13}{|c|}{ Panel A: Mean Parameters } \\
\hline$\mu=$ & {$\left[\begin{array}{c}0.259^{* * *} \\
0.192^{* * *} \\
-0.163^{* * *}\end{array}\right]$} & $\beta_{1}=$ & $\begin{array}{c}-0.180^{* * *} \\
-0.052^{* *} \\
-0.037\end{array}$ & $\begin{array}{c}0.119^{* * *} \\
-0.007 \\
0.193^{* * *}\end{array}$ & $\begin{array}{c}0.054^{* * *} \\
0.056^{* * *} \\
-0.196^{* * *}\end{array}$ & $\beta_{2}=$ & {$\left[\begin{array}{l}-0.074^{* * *} \\
-0.056^{* * *} \\
-0.077^{* * *}\end{array}\right.$} & $\begin{array}{l}0.073^{* * *} \\
0.048^{* * *} \\
0.148^{* * *}\end{array}$ & $\begin{array}{c}0.011 \\
0.020^{* *} \\
-0.098^{* * *}\end{array}$ & $\alpha=$ & {$\left[\begin{array}{c}-0.023^{* * *} \\
-0.021^{* * *} \\
0.015^{* * *}\end{array}\right.$} & $\begin{array}{c}0.024^{* * *} \\
0.027^{* * *} \\
-0.012^{* *}\end{array}$ \\
\hline
\end{tabular}

Panel B: Wald Tests of Restrictions on Mean Parameters

\section{$H_{0}$ : No Causality between Returns}

$\begin{array}{llcll}\text { Futures Brazil } \rightarrow \text { U.S.: } & \beta_{12,1}=\beta_{12,2}=0 & 27.18^{* * *} & \text { Spot Brazil } \rightarrow \text { U.S.: } & \beta_{13,1}=\beta_{13,2}=0 \\ \text { U.S. } \rightarrow \text { Futures Brazil: } & \beta_{21,1}=\beta_{21,2}=0 & 11.93^{* * *} & \text { Spot Brazil } \rightarrow \text { Futures Brazil: } & \beta_{23,1}=\beta_{23,2}=0 \\ \text { U.S. } \rightarrow \text { Spot Brazil: } & \beta_{31,1}=\beta_{31,2}=0 & 8.93^{* *} & \text { Brazil Futures } \rightarrow \text { Spot Brazil: } \quad \beta_{32,1}=\beta_{32,2}=0 & 14.93^{* * *} \\ & & 61.30^{* * *}\end{array}$

\footnotetext{
Panel C: Residual Diagnostics

$\begin{array}{lrrr}M V-Q(6) & 65.852[0.129] & M V-A R C H(6) & 208.05[0.638] \\ M V-Q(12) & 122.438[0.161] & M V-A R C H(12) & 397.160[0.884]\end{array}$

Panel A shows the parameter estimates for the conditional mean equations as specified in Eq. (1), where $\Delta p_{1, t}, \Delta p_{2, t}$, and $\Delta p_{3, t}$ are the returns of U.S. futures prices, Brazilian futures prices and Brazilian spot prices, respectively. Panel B contains the Chi-squared test statistics with two degrees of freedom for a Wald test on the conditional mean parameters. Panel C reports the multivariate $Q$-statistic and the multivariate ARCH test for 6 and 12 lags of the standardized residuals of our model. The corresponding $p$-values are shown in squared brackets. ${ }^{*},{ }^{* *},{ }^{* * *}$ denote statistical significance at the 10,5 , and 1 percent level, respectively.
} 
Table 4: Estimation Results of BEKK-GARCH-Model - Variance Equations

$$
H_{t}=C C^{\prime}+\left[\begin{array}{lll}
a_{11} & a_{12} & a_{13} \\
a_{21} & a_{22} & a_{23} \\
a_{31} & a_{32} & a_{33}
\end{array}\right]^{\prime} \varepsilon_{t-1} \varepsilon_{t-1}^{\prime}\left[\begin{array}{lll}
a_{11} & a_{12} & a_{13} \\
a_{21} & a_{22} & a_{23} \\
a_{31} & a_{32} & a_{33}
\end{array}\right]+\left[\begin{array}{lll}
b_{11} & b_{12} & b_{13} \\
b_{21} & b_{22} & b_{23} \\
b_{31} & b_{32} & b_{33}
\end{array}\right]^{\prime} H_{t-1}\left[\begin{array}{lll}
b_{11} & b_{12} & b_{13} \\
b_{21} & b_{22} & b_{23} \\
b_{31} & b_{32} & b_{33}
\end{array}\right]
$$

Panel A: Variance Parameters

$C=\left[\begin{array}{ccc}0.321^{* * *} & 0 & 0 \\ 0.050 & 0.135^{* * *} & 0 \\ 0.271^{* * *} & 0.135^{* * *} & 0.001\end{array}\right] \quad A=\left[\begin{array}{ccc}0.265^{* * *} & -0.075^{* * *} & 0.047 \\ -0.118^{* * *} & 0.228^{* * *} & -0.028 \\ 0.015 & -0.007 & 0.190^{* * *}\end{array}\right] \quad B=\left[\begin{array}{cccc}0.875^{* * *} & 0.034^{* * *} & -0.056^{* * *} \\ 0.122^{* * *} & 0.951^{* * *} & 0.059^{* * *} \\ -0.010^{*} & -0.001 & 0.972^{* * *}\end{array}\right]$

Panel B: Wald Tests of Restrictions on Volatility Spillover Coefficients

$\underline{H_{0}}$ : No Causality in Variance

\begin{tabular}{|c|c|c|c|c|c|}
\hline U.S. $\rightarrow$ Futures Brazil: & $a_{12}=b_{12}=0$ & $24.41^{* * *}$ & U.S. $\rightarrow$ Spot Brazil: & $a_{13}=b_{13}=0$ & $8.83^{* *}$ \\
\hline Futures Brazil $\rightarrow$ U.S.: & $a_{21}=b_{21}=0$ & $779.24^{* * *}$ & Futures Brazil $\rightarrow$ Spot Brazil: & $a_{23}=b_{23}=0$ & $10.17^{* * *}$ \\
\hline Spot Brazil $\rightarrow$ U.S.: & $a_{31}=b_{31}=0$ & 3.69 & Spot Brazil $\rightarrow$ Futures Brazil: & $a_{32}=b_{32}=0$ & 0.43 \\
\hline
\end{tabular}

Panel A contains the parameter estimates of the conditional variance equations as specified in Eq. (6). Panel B reports the Chi-squared test statistics with two degrees of freedom for a Wald test on the conditional variance parameters. ${ }^{*},{ }^{* *},{ }^{* * *}$ denote statistical significance at the 10,5 , and 1 percent level, respectively. 
Table 5: Estimates of BEKK-GARCH-Model with Shift Dummy

\begin{tabular}{|c|c|c|c|c|c|c|c|c|}
\hline \multirow[t]{2}{*}{$A=$} & \multirow[t]{2}{*}{$\begin{array}{c}a_{11} \\
a_{21}+a_{21 d} \cdot D \\
a_{31}+a_{31 d} \cdot D\end{array}$} & $\begin{array}{c}a_{12}+a_{12 d} \cdot D \\
a_{22} \\
a_{32}\end{array}$ & $\left.\begin{array}{c}a_{13}+a_{13 d} \cdot D \\
a_{23} \\
a_{33}\end{array}\right]$ & \multicolumn{3}{|c|}{$; B=\left[\begin{array}{c}b_{11} \\
b_{21}+b_{21 d} \cdot D \\
b_{31}+b_{31 d} \cdot D\end{array}\right.$} & $\begin{array}{c}b_{12}+b_{12 d} \cdot D \\
b_{22} \\
b_{32}\end{array}$ & $\left.\begin{array}{c}b_{13}+b_{13 d} \cdot D \\
b_{23} \\
b_{33}\end{array}\right]$ \\
\hline & & \multicolumn{7}{|c|}{ Panel A: Parameter Estimates of Cross-Border Spillover Coefficients } \\
\hline \multirow{2}{*}{\multicolumn{2}{|c|}{ U.S. $\rightarrow$ Futures Brazil }} & $a_{12}$ & $a_{12 d}$ & & $a_{12}+a_{12 d}$ & $b_{12}$ & $b_{12 d}$ & $b_{12}+b_{12 d}$ \\
\hline & & $-0.072^{* *}$ & -0.012 & & -0.084 & $0.037^{* * *}$ & 0.002 & 0.039 \\
\hline \multirow{2}{*}{\multicolumn{2}{|c|}{ U.S. $\rightarrow$ Spot Brazil }} & $a_{13}$ & $a_{13 d}$ & $\underline{c}$ & $a_{13}+a_{13 d}$ & $b_{13}$ & $b_{13 d}$ & $b_{13}+b_{13 d}$ \\
\hline & & 0.054 & -0.032 & & 0.020 & $-0.060^{* * *}$ & 0.003 & -0.055 \\
\hline \multirow{2}{*}{\multicolumn{2}{|c|}{ Futures Brazil $\rightarrow$ U.S. }} & $a_{21}$ & $a_{21 d}$ & & $a_{21}+a_{21 d}$ & $b_{21}$ & $b_{21 d}$ & $b_{21}+b_{21 d}$ \\
\hline & & $-0.104^{* * *}$ & $-0.090^{* *}$ & & -0.194 & $0.120^{* * *}$ & $0.009^{*}$ & 0.129 \\
\hline \multirow{2}{*}{\multicolumn{2}{|c|}{ Spot Brazil $\rightarrow$ U.S. }} & $a_{31}$ & $a_{31 d}$ & & $a_{31}+a_{31 d}$ & $b_{31}$ & $b_{31 d}$ & $b_{31}+b_{31 d}$ \\
\hline & & 0.006 & $0.084^{*}$ & & 0.090 & -0.008 & -0.005 & -0.013 \\
\hline
\end{tabular}

Panel B: Wald Tests of Restrictions on Spillover Coefficients

$\underline{H_{0}: \text { No Shift in Spillovers }}$

U.S. $\rightarrow$ Futures Brazil:

U.S. $\rightarrow$ Spot Brazil:

$a_{12 d}=b_{12 d}=0$
$a_{13 d}=b_{13 d}=0$
$a_{21 d}=b_{21 d}=0$
$a_{31 d}=b_{31 d}=0$

0.532

1.268

Futures Brazil $\rightarrow$ U.S.:

Spot Brazil $\rightarrow$ U.S.:

$6.871^{* *}$

3.908

Panel C: Residual Diagnostics

\begin{tabular}{llll}
\hline & Panel C: Residual Diagnostics & \\
\hline$M V-Q(6)$ & 64.26 & $M V-A R C H(6)$ & 218.14 \\
$M V-Q(12)$ & {$[0.16]$} & & {$[0.44]$} \\
& 129.01 & $M V-A R C H(12)$ & 410.06 \\
& {$[0.08]$} & & {$[0.76]$}
\end{tabular}

Panel A contains the parameter estimates for the cross-border spillover coefficients including the shift dummy parameters as written in Eqs. (7) and (8). The dummy period runs from June 16, 2010 to April 25, 2012, as suggested by the Bai and Perron $(1998,2003)$ breakpoint test procedure. Panel B shows the Chi-squared test statistics with two degrees of freedom for a Wald test on the shift dummy parameters. Panel C reports the multivariate $Q$-statistic and the multivariate ARCH test for 6 and 12 lags of the standardized residuals of our model. The corresponding $p$-values are shown in squared brackets. ${ }^{*},{ }^{* *},{ }^{* * *}$ denote statistical significance at the 10,5 , and 1 percent level, respectively. 